\title{
Risk for hip fracture before and after total knee replacement in Sweden
}

\author{
C.H. Vala ${ }^{1,2}$ (1) J. Kärrholm ${ }^{3}$ • J.A. Kanis ${ }^{4,5} \cdot$ H. Johansson ${ }^{1} \cdot$ S. Sten ${ }^{6} \cdot$ V. Sundh ${ }^{1} \cdot$ M. Karlsson ${ }^{7} \cdot$ M. Lorentzon ${ }^{1,2,5,8}$. \\ D. Mellström ${ }^{1,2,8}$
}

Received: 19 June 2019 / Accepted: 19 November 2019 / Published online: 12 December 2019

(C) The Author(s) 2019

\begin{abstract}
Summary We studied the risk for hip fracture before and after total knee replacement (TKR) in the entire population in Sweden. Women and men had a low risk for hip fracture before TKR but an increased risk the first year after TKR.

Purpose It is known that osteoarthritis is associated with high bone mass. We therefore studied the risk of hip fracture before and after total knee replacement (TKR), risk of different hip fracture types, and risk subdivided in genders and age groups.

Methods We followed the total Swedish population born between 1902 and $1952(n=4,258,934)$ during the period 1987-2002 and identified all patients with TKR due to primary OA $(n=39,291)$, and all patients with hip fracture $(n=195,860)$ in the Swedish National Inpatient Register. The risk time analyses were based on Poisson regression models.

Results The hazard ratio (HR) for hip fracture the last year before TKR was 0.86 (95\% CI 0.74 to 1.00 ) and the first year after 1.26 (95\% CI 1.11 to 1.42) compared to individuals without TKR. The HR for femoral neck fracture 0-10 years after TKR was 0.95 (95\% CI 0.89 to 1.01) and for trochanteric fracture was 1.13 (95\% CI 1.06 to 1.21). The HR for hip fracture in the age group 50-74 was 1.28 (95\% CI 1.14 to 1.43) and in the age group 75-90 years was 0.99 (95\% CI 0.94 to 1.04 ) $0-10$ years after TKR, compared to individuals without TKR.

Conclusion Individuals had a low risk for hip fracture before TKR but an increased risk the first year after TKR. The risk in individuals below age 75 years and for trochanteric fractures was increased after TKR. Possible explanations include changed knee kinematics after a TKR, physical activity level, fall risk, and other unknown factors.
\end{abstract}

Keywords Femur neck fracture · Hip fracture · Osteoarthritis · Total knee replacement · Trochanteric fracture

\section{Introduction}

Osteoarthritis is a widespread disease, and, according to the Global Burden of Disease (GBD) 2010 study, osteoarthritis is ranked as number eleven in terms of disability [1]. Risk factors are age, gender, genetics (40\% in knee osteoarthritis), overweight/obesity, congenital anomalies, and injury including

C.H. Vala

cecilie.hongslo.vala@gu.se

1 Geriatric Medicine, Department of Internal Medicine and Clinical Nutrition, Sahlgrenska Academy, University of Gothenburg, 413 45 Göteborg, Sweden

2 Region Västra Götaland, Geriatric Medicine Clinic, Sahlgrenska University Hospital, 43180 Mölndal, Sweden

3 Department of Orthopedic Surgery, Sahlgrenska Academy, University of Gothenburg, 43180 Mölndal, Sweden repetitive trauma $[2,3]$. Knee osteoarthritis is more common in women and is associated with occupation for men $[4,5]$.

In orthopaedic surgery, total knee replacement (TKR) is one of the most widespread surgical procedures. In 2017, 13,689 TKR were performed in Sweden, and 9\% of women and $7 \%$ of men in the age group $80-85$ years have at least one knee prosthesis [6]. The mean age for TKR was 68.9 years

4 Centre for Metabolic Bone Disease, Medical School, University of Sheffield, S10 2RX, Sheffield, UK

5 Mary McKillop Health Institute, Australian Catholic University, Melbourne, VIC 3000, Australia

6 Department of Archaeology and Ancient History, Uppsala University- Campus Gotland, 62157 Visby, Sweden

7 Department of Orthopedics and Clinical Sciences, Lund University, Skåne University Hospital, 20502 Malmö, Sweden

8 Center for Bone and Arthritis Research (CBAR), Sahlgrenska Academy, University of Gothenburg, 41345 Gothenburg, Sweden 
with a gender distribution of $44 \%$ men and $56 \%$ women [6]. Due to the expected increase in body weight in the population and an increased older population, the total number of TKR will most likely increase in the future, with an expected level of 17,500 TKR in 2020 in Sweden [7]. Patients selected for surgery often have severe clinical and radiographic findings and self-reported pain [8]. TKR is then an effective treatment that relieves pain and improves physical mobility [9].

Today we know too little about the association between osteoarthritis, falls, and fractures. Several studies have reported an association between high bone mineral density (BMD) and osteoarthritis [10]. In contrast, other reports infer that both women and men with osteoarthritis also may have osteoporosis or osteopenia [11, 12] and an increased risk of falls and fracture $[10,11,13]$.

Hip fractures are related to a high mortality rate and reduced physical function [14]. Sweden has one of the highest known hip fracture incidences in the world, but the underlying reasons are not clear [14]. Risk factors for hip fracture include age, height, genetic factors, and lifestyle factors such as physical inactivity, diet, alcohol consumption and smoking, a low body mass index (BMI), low BMD, and hip geometry [14, 15].

A British study found that the risk of hip fracture was increased by $58 \%$ (after adjusting for age, gender, BMI, smoking, and alcohol intake) the first year after TKR, a finding that was supported by a Dutch study, which found that the probability of a hip fracture increased with $54 \%$ after TKR $[16,17]$. To the best of our knowledge, these are the only studies available on the risk of hip fracture before and after TKR, and none has been found regarding the risk of femur neck and trochanteric fracture in a 10-year period before and after TKR.

Our primary aim in this study was to examine the risk for hip fracture before and after TKR. Secondary aims in this study were to examine if there were any gender differences in the risk and if there were different risks among patients in different age strata. We also wanted to investigate if there were different risks for femoral neck and trochanteric fracture, due to the differences in morphology, geometry, and aetiology between the two hip fracture types [18].

\section{Materials and methods}

\section{Outcomes}

The admissions to Swedish hospitals for TKR and hip fracture were studied between January 1987 and December 2002. The data came from the Swedish National Inpatient Register, which continuously registers each hospital admission. Each individual had a unique personal identifier to avoid registration of multiple admissions. The accuracy for surgical procedures is high and exceeds $90 \%$ in the registers [19]. The International Classification of Diseases (ICD), 9th and 10th revisions were used to identify the patients. The patients were required to have ICD codes for primary osteoarthritis (ICD-9 715B or ICD-10 M17), hip fracture (ICD-9 820A-D or ICD-10 S720-722), and ICD codes for surgical procedures for TKR (ICD-9 8428 or ICD-10 NGB 29, NGB 39 and NGB 49) and hip fracture (ICD-9 8200-8219, 8413-8414 or ICD-10 NFB, NFJ).

\section{Cohort}

Data for this study comprised the entire Swedish population, born between 1902 and 1952, in the Swedish Total Population Register from 1986 ( $n=4,546,636)$. The following exclusion criteria were applied:

1. Hip fracture diagnosis in hospital registers without a corresponding procedure code

2. Knee replacement procedure without diagnosis code for primary knee osteoarthritis

3. Surgical procedure for insertion of osteosynthetic material in the hip, including THR, with the exception of corresponding diagnosis code for hip fracture

4. Risk time in men and women below the age of 50 years and above the age of 90 years due to few TKRs (126 and 38 , respectively)

After exclusion of individuals meeting any of the above criteria in the study period 1987 to 2002 , there were $4,258,934$ persons remaining; $2,190,638$ women $(51.4 \%)$ and 2,068,296 men (48.6\%). Additional information for all persons included was obtained from the Swedish National Inpatient Register at the Swedish National Board of Health and Welfare from 1987 to 2002, identifying all hospital episodes with musculoskeletal diagnoses and related surgical procedures. Data from the Swedish National Inpatient Register were combined with data from the Swedish Total Population Register and the Swedish Census Registers, supplied by Statistics Sweden, with information on place of residence, income, and level of education. In the study population, we included women and men between 50 and 90 years with a diagnosis code for primary knee osteoarthritis and a corresponding surgical code for TKR. The control population consisted of women and men between 50 and 90 years without an event of TKR during the follow-up period. Neither the study population nor the control population had any hospital episode of THR during the follow-up period.

We performed analysis subdivided into age, sex, and type of hip fracture, femoral neck fractures and trochanteric fractures, to see the effect on risk of hip fracture associated to TKR. Trochanteric fractures include both intertrochanteric and subtrochanteric fracture. We divided the study population 
in two age groups; 50-74 years and 75-90 years, since we did not have power to divide into one age group per decade.

\section{Covariates}

The relationship between TKR and risk for hip fracture was analysed with the following covariates: age, gender, calendar year for fracture, and latitude. Additional adjustment for income, education, and level of urbanization of place of residence, previously associated with hip fracture [20,21], had no effect on the relationship between hip fracture risk and TKR, so these variables were not included. For more detailed information on distribution of income, education and urbanization, we refer to our previous studies [20,21]. We had no information on BMI, BMD, comorbidity, or physical activity.

\section{Statistical analysis}

In the Swedish National Inpatient Register, each individual was followed from January 1, 1987 until December 31, 2002 to capture the first event of TKR, hip fracture, or date of death in this period. We assumed that the admission dates were the same as the fracture or surgery date.

The relationship between TKR and the risk of hip fracture, along with covariates, was studied with an extension of Poisson regression model [22], which utilizes the length of each individual's follow-up period. The individual risk time was divided into periods of 2 months, with outcome coded as 0 in periods without a studied event and 1 in periods with an event. The results are reported as hazard ratios (HR) with 95\% confidence interval (CI) and are comparable with results from a Cox proportional hazard model. We presented the results in the time periods $10+$ years before and after TKR, $0-10$ years before and after TKR, 5-10 years before and after TKR, $0-5$ years before and after TKR, and $1-0$ years before TKR, and $0-1$ years after TKR.

\section{Results}

The mean follow-up time was 10.01 years \pm 5.3 standard deviation (SD) for all individuals and for individuals with hip fracture was 8.2 years $\pm 4.5 \mathrm{SD}$ years. The total risk time in the age interval 50-90 years included 43,608,329 person-years for outcome hip fracture. Patients with TKR were followed for 348,952 person-years prior to surgery, and during this period, 800 hip fractures occurred, which correspond to an age standardized incidence of 2.77 cases per 1000 years. Total risk time for hip fracture incidence after TKR equalled 207,438 person-years with 2248 cases of hip fracture, corresponding to an age standardized incidence of 5.40 per 1000 years. Persons without TKR during 1987-2002 were followed for 43,051,939 person-years with 192,807 hip fractures, corresponding to an incidence of 4.50 per 1000 years.

The number of TKRs due to primary osteoarthritis in the age interval 50-90 years was 39,291 (25,490 women and 13,801 men) between 1987 and 2002. During this time, 3048 of these patients, mainly women $(77.8 \%)$, also had a hip fracture. Of the hip fractures, 1606 were femoral neck fracture, 1439 were trochanteric fracture, and 3 had combined femur neck and trochanteric fracture. The majority of the patients with TKR and hip fracture sustained the fracture after TKR $(n=2248)$. Of these, 1136 were femoral neck fractures, 1109 were trochanteric fractures, and 3 combined femur neck and trochanteric fracture.

A total of 195,860 hospital discharges where the patient had been treated for hip fracture were found between 1987 and 2002 in Sweden. The majority, 138,644 (70.8\%), of the patients were women while 57,216 (29.2\%) were men. Of the hip fractures, 109,093 (71\% women) were femoral neck fractures and 86,324 (70.5\% women) were trochanteric fractures, and 443 were combined femur neck and trochanteric fracture. The combination with TKR was equally common for both types of hip fracture.

The mean age for TKR was $72.1 \pm 7.6$ SD years (women $72.4 \pm 7.6 \mathrm{SD}$ years and men $71.5 \pm 7.6 \mathrm{SD}$ years). The mean age for hip fracture was $78.8 \pm 8.2 \mathrm{SD}$ years (women $79.4 \pm$ 7.8 SD years and men 77.3 $\pm 8.9 \mathrm{SD}$ years). The mean age for when individuals with TKR sustained hip fracture was $78.8 \pm$ 8.2 SD years (women $78.9 \pm 6.7$ SD years and men $78.3 \pm 7.3$ SD years). The mean age for femur neck fracture was $78.3 \pm$ 8.3 SD years and for trochanteric fracture was $79.4 \pm 8.1 \mathrm{SD}$ years. Women with trochanteric fracture had an increased mean age by 1.78 (95\% CI 1.70 to 1.86 ) years compared to women with femoral neck fracture, while men with trochanteric fracture had a decreased mean age by 0.64 (95\% CI-0.79 to -0.50 ) years compared to men with femoral neck fracture. Table 1 gives more characteristics of the TKR population and controls.

\section{Risk of hip fracture before and after TKR}

In the last year before TKR, the risk for hip fracture was decreased (HR 0.86 ; 95\% CI 0.74 to $1.00, p=0.0486$ ) compared to the control population. In the first year after TKR, the risk for hip fracture was increased by $26 \%$ (95\% CI 1.11 to 1.42) compared to the control population. There was a $46 \%$ increased risk (95\% CI 1.21 to 1.77) for hip fracture when directly comparing the last year before TKR with the first year after TKR. The risk for hip fracture in the 10-year period before TKR was lower (HR $0.61 ; 95 \%$ CI 0.57 to 0.66 ), but the risk in the 10-year period after TKR was not significantly different than in individuals without TKR (HR 1.03; 95\% CI 0.99 to 1.08 ). There was an increased risk of almost $70 \%$ (95\% CI 1.55 to 1.83 ) for hip fracture when directly 
Table 1 Baseline characteristics for individuals with or without total knee replacement

\begin{tabular}{lll}
\hline & $\begin{array}{l}\text { Total knee replacement } \\
n=39,291\end{array}$ & $\begin{array}{l}\text { No total knee replacement } \\
n=4,219,643\end{array}$ \\
\hline Women & $64.9 \%$ & $51.3 \%$ \\
Mean age (years) & $63.2 \pm 8.07$ & $59.1 \pm 10.5$ \\
Income & & \\
Lowest quintile & $19.7 \%$ & $18.2 \%$ \\
2nd quintile & $23.0 \%$ & $20.3 \%$ \\
3rd quintile & $20.7 \%$ & $20.4 \%$ \\
4th quintile & $19.1 \%$ & $20.6 \%$ \\
Highest quintile & $17.5 \%$ & $20.5 \%$ \\
Education & & \\
$\leq 9$ years & $66.6 \%$ & $52.7 \%$ \\
10-12 years & $29.3 \%$ & $39.0 \%$ \\
University & $4.2 \%$ & $8.3 \%$ \\
Latitude & & \\
South & $25.2 \%$ & $20.8 \%$ \\
Middle-south & $45.0 \%$ & $51.4 \%$ \\
Middle-north & $19.4 \%$ & $16.9 \%$ \\
North & $10.4 \%$ & $10.8 \%$ \\
Population density $(000)$ & $13.6 \%$ \\
$>$ 200 & $13.2 \%$ & $32.3 \%$ \\
$50-200$ & $29.5 \%$ & $35.1 \%$ \\
15-50 & $37.6 \%$ & $16.6 \%$ \\
$<15$ & $19.7 \%$ & \\
\hline
\end{tabular}

comparing the 10-year period before TKR with the 10-year period after TKR. Table 2 presents the risk of hip fracture before and after TKR in different time periods, in both women and men combined and according to gender.

\section{Risk for hip fracture according to gender}

Women and men had a low risk for hip fracture before TKR (Table 2). In the 10-year period after TKR, the risk for hip fracture in women was not significantly different from the risk of hip fracture in the control population (HR 1.01; 95\% CI
0.96 to 1.07$)$. For men, the risk of hip fracture was increased compared to the control population (HR 1.10; 95\% CI 1.01 to 1.21).

\section{Risk for hip fracture in two age groups}

The age group 50-74 years had a low risk for hip fracture in the 10 -year period before surgery (HR $0.69 ; 95 \%$ CI 0.62 to 0.77 ) and a $28 \%$ (95\% CI 1.14 to 1.43 ) increased risk of hip fracture in the 10-year period after TKR, compared to the control population. In the investigated time interval after the 10 -year period after TKR, there was a $96 \%$ increased risk for hip fracture, compared to the control population (Table 3). In the age group 75-90 years, the risk for hip fracture in the 10year period before surgery was low (HR 0.56 ; $95 \%$ CI 0.51 to 0.62 ), but in the 10-year period after TKR, the risk was not significantly different from the control population (HR 0.99; 95\% CI 0.94 to 1.04). Table 3 presents risk for hip fracture in different time periods before and after TKR according to age.

\section{Risk for femoral neck and trochanteric fracture}

We observed an increasing trend in the proportions of trochanteric fractures with increased age among all women with hip fracture. For femoral neck fracture, we observed a decreasing trend with increased age. Women had a larger proportion of femoral neck fracture up to the age of 85 years; after 85 years, the majority of hip fractures were trochanteric fractures. Studying the total amount of hip fracture in all ages, femoral neck fractures were in majority (55.3\%). For men, femoral neck fractures were in majority in all ages, also when looking at the total amount of hip fractures combined in all ages $(55.4 \%)$.

In the 10-year period before TKR, the risk for femoral neck fracture (HR $0.62 ; 95 \%$ CI 0.56 to 0.68 ) and trochanteric fracture (HR $0.61 ; 95 \%$ CI 0.55 to 0.68 ) were low compared to the control population. In the 10 -year period after TKR, the risk for femoral neck fracture was not significantly different from the control population (HR $0.95 ; 95 \%$ CI 0.89 to 1.01 ), while the risk for trochanteric fracture was higher (HR 1.13;

Table 2 The hazard ratios (with 95\% CI) for hip fracture before and after total knee replacement (TKR), according to gender, compared to individuals without TKR

\begin{tabular}{lllr}
\hline Time interval & All & Women & Men \\
\hline$>10$ years before & $0.42(0.30-0.58)$ & $0.45(0.31-0.64)$ & $0.34(0.16-0.72)$ \\
$5-10$ years before & $0.47(0.40-0.55)$ & $0.46(0.39-0.55)$ & $0.50(0.37-0.69)$ \\
$0-5$ years before & $0.67(0.62-0.72)$ & $0.67(0.61-0.73)$ & $0.67(0.56-0.79)$ \\
$0-5$ years after & $1.05(0.99-1.11)$ & $1.03(0.97-1.10)$ & $1.09(0.96-1.22)$ \\
$5-10$ years after & $1.01(0.94-1.09)$ & $0.98(0.91-1.06)$ & $1.13(0.98-1.32)$ \\
$>10$ years after & $1.00(0.88-1.15)$ & $0.95(0.82-1.10)$ & $1.26(0.95-1.68)$ \\
\hline
\end{tabular}

The models were adjusted for age, gender, calendar year, and latitude 
Table 3 The hazard ratios (with 95\% CI) for hip fracture before and after total knee replacement (TKR), according to age, compared to individuals without TKR

\begin{tabular}{lll}
\hline Time interval & 50-74 years & 75-90 years \\
\hline$>10$ years before & $0.46(0.33-0.63)$ & $0.11(0.01-0.75)$ \\
$5-10$ years before & $0.52(0.43-0.63)$ & $0.40(0.30-0.52)$ \\
$0-5$ years before & $0.81(0.72-0.92)$ & $0.60(0.54-0.66)$ \\
$0-5$ years after & $1.28(1.13-1.46)$ & $1.00(0.94-1.06)$ \\
$5-10$ years after & $1.26(1.00-1.59)$ & $0.98(0.91-1.06)$ \\
$>10$ years after & $1.96(1.18-3.26)$ & $0.96(0.83-1.10)$ \\
\hline
\end{tabular}

Analyses were performed in separate age-bands and adjusted for age, gender, calendar year, and latitude

95\% CI 1.06 to 1.21$)$ compared to the control population. There was a 53\% higher risk for femur neck fracture $(95 \%$ CI 1.37 to 1.71 ) and an $85 \%$ higher risk for trochanteric fracture $(95 \%$ CI 1.63 to 2.10 ) from the 10-year period before TKR to the 10-year period after TKR. In the 10 -year period after TKR, women had a $61 \%$ higher risk for femoral neck fracture (95\% CI 1.39 to 1.87 ) and $71 \%$ higher risk for trochanteric fracture (95\% CI 1.47 to 1.99) compared to men. Figure 1 presents risk for femoral neck fracture and trochanteric fracture in different time periods, while Table 4 shows the risk for femoral neck fracture and trochanteric fracture according to age.

\section{Discussion}

Our results revealed a $14 \%$ lower risk for hip fracture the last year before TKR, while in the first year after TKR, the hip fracture risk was increased by $26 \%$, compared to the control population. The increased risk of hip fracture from the last year before to the first year after TKR was significant. Studying a 10-year period, the risk of hip fracture was $39 \%$ lower before TKR, but in the 10-year period after TKR, the risk was not significantly different from the control population. We did, however, observe an increased risk by almost $70 \%$ from the 10 -year period before TKR to the 10 -year period after TKR. Studying the risk for hip fracture in subgroups in the 10-year period after TKR, we found that men had a $10 \%$ increased risk, individuals below 75 years old had a $28 \%$ increased risk, and the risk for trochanteric fractures was increased by $13 \%$, compared to the control population. However, women had a $26 \%$ increased risk of hip fracture the first year after TKR, compared to the control population.

Supportive of our studies are a British and a Dutch study. The British study of 20,033 patients with TKR identified an adjusted 58\% (95\% CI 1.14 to 2.19) increase in hip fracture risk the first year after surgery, compared to the control population $(n=100,165)$ with no knee problems [17]. In this study, information was available for previous fracture, comorbidity, BMI, smoking status, and alcohol intake [17]. A Dutch study of 6763 hip fracture patients, where 89 had knee arthroplasty, also found a higher possibility for hip fracture (OR 1.54; 95\% CI 1.19-2.00) after TKR [16].

\section{BMD, BMI, falls, and fracture}

Individuals with osteoarthritis have been found to have high $\mathrm{BMI}$, poorer bone strength and quality despite high BMD, and increased risk for both falls and fracture [10]. Though, some studies have instead found no increased or decreased risk for fracture $[10,23]$. Studies of the relationship between osteoarthritis, BMD, fall risk, and fracture risk have resulted in conflicting results [10].

A lower BMD after TKR has been shown in the majority of the studies conducted in this area [10]. The greatest loss of $\mathrm{BMD}$, found in both the operated area and in the hip, was found within the first 3-6 months after surgery, levelling out from 2 years after the surgery [10]. The bone loss might be attributed to the presumed reduction in mobility after TKR [10]. A study of 238 persons with TKR revealed that there were only small changes in physical activity 6 months after TKR, and the activity level was still lower than in healthy controls after 1 year [24]. There have been several studies showing an increased risk for falls after TKR [25, 26]. Risk
Fig. 1 Hazard ratio for femur neck and trochanteric fracture before and after total knee replacement (TKR), adjusted for age, gender, calendar year, and latitude

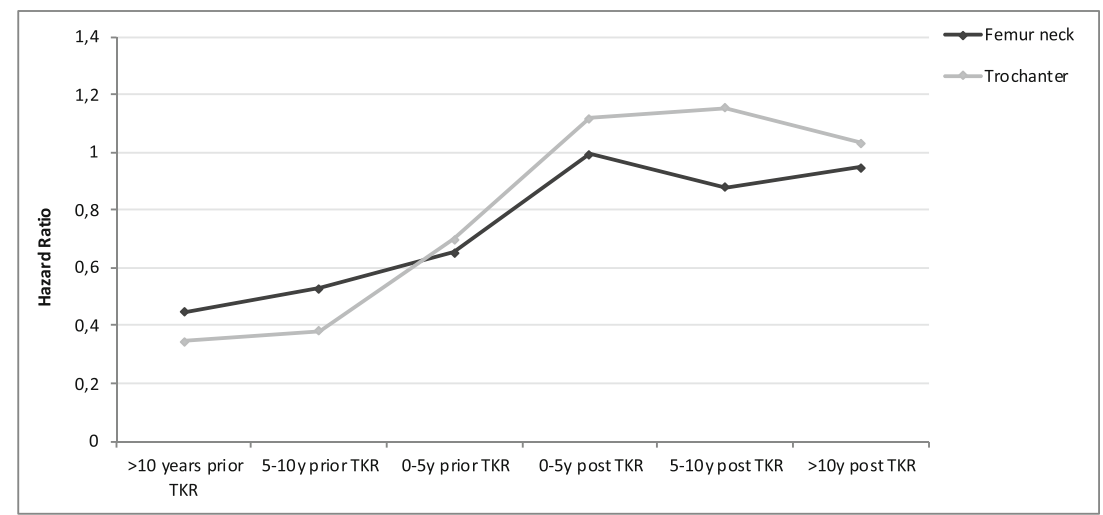


Table 4 The hazard ratios (with 95\% CI) for hip fracture before and after total knee replacement (TKR), according to fracture type and age, compared to individuals without TKR

\begin{tabular}{|c|c|c|c|c|}
\hline \multirow[t]{2}{*}{ Time interval } & \multicolumn{2}{|c|}{ Femur neck fracture } & \multicolumn{2}{|c|}{ Trochanteric fracture } \\
\hline & 50-74 years & 75-90 years & $50-74$ years & $75-90$ years \\
\hline$>10$ years before & $0.52(0.35-0.78)$ & $0.20(0.03-1.39)$ & $0.42(0.24-0.74)$ & NA \\
\hline $5-10$ years before & $0.61(0.48-0.76)$ & $0.51(0.36-0.71)$ & $0.48(0.35-0.65)$ & $0.31(0.19-0.51)$ \\
\hline $0-5$ years before & $0.76(0.64-0.90)$ & $0.65(0.57-0.75)$ & $1.01(0.84-1.21)$ & $0.61(0.52-0.71)$ \\
\hline $0-5$ years after & $1.29(1.09-1.53)$ & $0.99(0.90-1.07)$ & $1.43(1.18-1.74)$ & $1.12(1.03-1.23)$ \\
\hline $5-10$ years after & $1.19(0.87-1.64)$ & $0.90(0.81-1.00)$ & $1.54(1.10-2.15)$ & $1.19(1.07-1.31)$ \\
\hline$>10$ years after & $1.40(0.63-3.12)$ & $0.99(0.82-1.20)$ & $3.00(1.56-5.77)$ & $1.03(0.85-1.26)$ \\
\hline
\end{tabular}

Analyses were performed in separate age-bands and adjusted for age, gender, calendar year, and latitude. NA not applicable

factors for falls included female gender, psychiatric disease, medications, previous falls and previous TKR, and living alone [25].

Women and men with osteoarthritis tend to have a higher BMI $[11,13]$. Obese individuals tend to have increased BMD but are also associated with a lower rate of bone formation [10]. Overweight and obesity have in most studies shown to protect against hip fracture $[27,28]$. A higher BMI in women and men with knee osteoarthritis could therefore be an explanation for the lower risk for hip fracture we found in the period before TKR. However, obesity is an inflammatory condition with an increased risk for type 2 diabetes and cardiovascular disease, and low muscle mass and low physical performance are associated with obesity $[27,29]$. These are all risk factors for hip fracture, and abdominal obesity have been associated with an increased risk for hip fracture [28, 30-33].

\section{Comorbidity}

In a Swedish study of 1299 TKRs, almost $25 \%$ of the patients reported other diseases [8]. A Danish study showed that patients after TKR experienced leg oedema (90.7\%), pain $(81.4 \%)$, sleeping disorders $(47.7 \%)$, and as many as $69.8 \%$ reported low physical activity [34]. These conditions can possibly contribute to an increased hip fracture risk.

\section{Kinematics}

After insertion of TKR, the knee does not resume normal kinematics [35], and any misalignment, especially too much internally rotated components, will influence patellar tracking and the risk for falling [36]. It could, however, be argued that the kinematics of the knee is also abnormal in the osteoarthritic knee [37, 38], but to which extent, these changes of the pattern of knee motion before and after the insertion of a TKR influence the risk of falling is poorly understood.

\section{Risk for femoral neck and trochanteric fractures after TKR}

More research is needed to explain why there is an increased risk of trochanteric fracture after TKR in our study, but perhaps one explanation might be that the possible immobility or low physical activity both before and after TKR might have led to lower BMD and bone quality. Individuals with trochanteric fractures are often older and have lower BMD and are therefore more osteoporotic than individuals with femoral neck fracture [18, 39]. A review study, including only women, has shown that the location of the hip fracture was not determined by fall biomechanics and that the geometrics of the hip and femur were different in the two hip fracture types [18]. Comparing geometrical features of the two fracture types, women with trochanteric fracture had a decreased cortical thickness in the femoral shaft, while women with femoral neck fracture had an increased femoral head, a decreased cortical thickness of the femoral neck, and an increased acetabular bone width [18]. There might also be a connection between type of knee osteoarthritis (lateral, medial, both) and type of fracture. A previous Swedish study has shown that the anatomy of the hip and pelvis differ between individuals with lateral and medial knee osteoarthritis [40].

\section{Strengths and limitations of the study}

The large study size is a strength of this study. We had a long follow-up period where we could follow the population between the years 1987 and 2002, a period of 16 years. We had information on age, gender, latitude, urbanization, income, education, type of hip fracture, and death. The information received from the Swedish registers have a high validity, especially the information on hip fracture and TKR. All individuals admitted to hospitals will automatically be registered in the Swedish National Inpatient Register.

A limitation of our study was that cases of hip fracture and TKR, which occurred before 1987 and after 2002, were not 
included in this study. Nor did we have any information on which side surgery or hip fracture occurred. Thus, some of the individuals who were studied before insertion of a TKR could have had a TKR inserted on the opposite side without our knowledge. We do not know how or if bilateral TKR affects the results. Some could also have had unilateral or bilateral THR before 1987. These individuals would therefore have had lower or no risk for hip fracture. There is also a possibility that periprosthetic fractures may have occurred in the trochanteric region and might have been misclassified as a pertrochanteric fracture. We do, however, consider that the number of such cases is small and without any significant influence on our results [41]. There might be a selection bias to healthier patients being operated with a TKR, which might affect the results for both before and after TKR, and most likely towards a lower risk of fracture. We had no information on comorbidity and other covariates that might affect risk of hip fracture, such as physical activity, height, weight, BMI, BMD, diet, smoking, and alcohol habits.

\section{Conclusion}

Our study indicates that patients with knee osteoarthritis have a lower risk for hip fracture before TKR compared to individuals without TKR. In the first year after surgery, the risk for hip fracture was increased. However, studying the 10-year period after TKR, the risk for hip fracture was not significantly different from the risk for hip fracture in the control population. Sub-studies showed increased risk of hip fracture in the age group 50 to 74 years, in men, and for trochanteric hip fractures. Possible explanations for the increased hip fracture risk after TKR might be bone loss, changed knee kinematics, reduced mobility, pain, and increased fall risk, but other unknown factors should also be considered. Selection bias from surgeons might also have an effect on the results both before and after TKR.

Acknowledgements The authors are grateful to professor Anders Odén and late professor Olof Johnell for contributing to the collection of data. The authors also thank Dr Kate Bramley-Moore for English language proofreading assistance. The study was funded by grants from the Swedish state under the agreement between the Swedish government and the county councils, the ALF-agreement (ALFGBG722321 and ALFGBG437971), The Swedish Research Council (2017-02229).

Funding Information Open access funding provided by University of Gothenburg.

\section{Compliance with ethical standards}

Ethical statement All procedures performed in studies involving human participants were in accordance with the ethical standards of the institutional and/or national research committee and with the 1964 Helsinki declaration and its later amendments or comparable ethical standards.
All data received from Statistics Sweden and the Swedish National Board of Health and Welfare were coded, but we have ethics approval (LU 630-99). For this retrospective study formal consent is not required.

Conflicts of interest The authors declare that they have no conflict of interest.

Open Access This article is distributed under the terms of the Creative Commons Attribution-NonCommercial 4.0 International License (http:// creativecommons.org/licenses/by-nc/4.0/), which permits any noncommercial use, distribution, and reproduction in any medium, provided you give appropriate credit to the original author(s) and the source, provide a link to the Creative Commons license, and indicate if changes were made.

\section{References}

1. Vos T, Flaxman AD, Naghavi M, Lozano R, Michaud C, Ezzati M, Shibuya K, Salomon JA, Abdalla S, Aboyans V, Abraham J, Ackerman I, Aggarwal R, Ahn SY, Ali MK, Alvarado M, Anderson HR, Anderson LM, Andrews KG, Atkinson C, Baddour LM, Bahalim AN, Barker-Collo S, Barrero LH, Bartels DH, Basáñez MG, Baxter A, Bell ML, Benjamin EJ, Bennett D, Bernabé E, Bhalla K, Bhandari B, Bikbov B, Bin Abdulhak A, Birbeck G, Black JA, Blencowe H, Blore JD, Blyth F, Bolliger I, Bonaventure A, Boufous S, Bourne R, Boussinesq M, Braithwaite T, Brayne C, Bridgett L, Brooker S, Brooks P, Brugha TS, BryanHancock C, Bucello C, Buchbinder R, Buckle G, Budke CM, Burch M, Burney P, Burstein R, Calabria B, Campbell B, Canter CE, Carabin H, Carapetis J, Carmona L, Cella C, Charlson F, Chen H, Cheng AT, Chou D, Chugh SS, Coffeng LE, Colan SD, Colquhoun S, Colson KE, Condon J, Connor MD, Cooper LT, Corriere M, Cortinovis M, de Vaccaro KC, Couser W, Cowie BC, Criqui MH, Cross M, Dabhadkar KC, Dahiya M, Dahodwala N, Damsere-Derry J, Danaei G, Davis A, de Leo D, Degenhardt L, Dellavalle R, Delossantos A, Denenberg J, Derrett S, Des Jarlais DC, Dharmaratne SD, Dherani M, Diaz-Torne C, Dolk H, Dorsey ER, Driscoll T, Duber H, Ebel B, Edmond K, Elbaz A, Ali SE, Erskine H, Erwin PJ, Espindola P, Ewoigbokhan SE, Farzadfar F, Feigin V, Felson DT, Ferrari A, Ferri CP, Fèvre EM, Finucane MM, Flaxman S, Flood L, Foreman K, Forouzanfar MH, Fowkes FG, Franklin R, Fransen M, Freeman MK, Gabbe BJ, Gabriel SE, Gakidou E, Ganatra HA, Garcia B, Gaspari F, Gillum RF, Gmel G, Gosselin R, Grainger R, Groeger J, Guillemin F, Gunnell D, Gupta R, Haagsma J, Hagan H, Halasa YA, Hall W, Haring D, Haro JM, Harrison JE, Havmoeller R, Hay RJ, Higashi H, Hill C, Hoen B, Hoffman H, Hotez PJ, Hoy D, Huang JJ, Ibeanusi SE, Jacobsen KH, James SL, Jarvis D, Jasrasaria R, Jayaraman S, Johns N, Jonas JB, Karthikeyan G, Kassebaum N, Kawakami N, Keren A, Khoo JP, King CH, Knowlton LM, Kobusingye O, Koranteng A, Krishnamurthi R, Lalloo R, Laslett LL, Lathlean T, Leasher JL, Lee YY, Leigh J, Lim SS, Limb E, Lin JK, Lipnick M, Lipshultz SE, Liu W, Loane M, Ohno SL, Lyons R, Ma J, Mabweijano J, MacIntyre M, Malekzadeh R, Mallinger L, Manivannan S, Marcenes W, March L, Margolis DJ, Marks GB, Marks R, Matsumori A, Matzopoulos R, Mayosi BM, McAnulty J, McDermott M, McGill N, McGrath J, Medina-Mora ME, Meltzer M, Mensah GA, Merriman TR, Meyer AC, Miglioli V, Miller M, Miller TR, Mitchell PB, Mocumbi AO, Moffitt TE, Mokdad AA, Monasta L, Montico M, Moradi-Lakeh M, Moran A, Morawska L, Mori R, Murdoch ME, Mwaniki MK, Naidoo K, Nair MN, Naldi L, Narayan KM, Nelson PK, Nelson RG, Nevitt MC, Newton CR, 
Nolte S, Norman P, Norman R, O'Donnell M, O'Hanlon S, Olives C, Omer SB, Ortblad K, Osborne R, Ozgediz D, Page A, Pahari B, Pandian JD, Rivero AP, Patten SB, Pearce N, Padilla RP, PerezRuiz F, Perico N, Pesudovs K, Phillips D, Phillips MR, Pierce K, Pion S, Polanczyk GV, Polinder S, Pope CA 3rd, Popova S, Porrini E, Pourmalek F, Prince M, Pullan RL, Ramaiah KD, Ranganathan D, Razavi H, Regan M, Rehm JT, Rein DB, Remuzzi G, Richardson K, Rivara FP, Roberts T, Robinson C, de Leòn FR, Ronfani L, Room R, Rosenfeld LC, Rushton L, Sacco RL, Saha S, Sampson U, Sanchez-Riera L, Sanman E, Schwebel DC, Scott JG, Segui-Gomez M, Shahraz S, Shepard DS, Shin H, Shivakoti R, Singh D, Singh GM, Singh JA, Singleton J, Sleet DA, Sliwa K, Smith E, Smith JL, Stapelberg NJ, Steer A, Steiner T, Stolk WA, Stovner LJ, Sudfeld C, Syed S, Tamburlini G, Tavakkoli M, Taylor HR, Taylor JA, Taylor WJ, Thomas B, Thomson WM, Thurston GD, Tleyjeh IM, Tonelli M, Towbin JA, Truelsen T, Tsilimbaris MK, Ubeda C, Undurraga EA, van der Werf M, van Os J, Vavilala MS, Venketasubramanian N, Wang M, Wang W, Watt K, Weatherall DJ, Weinstock MA, Weintraub R, Weisskopf MG, Weissman MM, White RA, Whiteford H, Wiersma ST, Wilkinson JD, Williams HC, Williams SR, Witt E, Wolfe F, Woolf AD, Wulf S, Yeh PH, Zaidi AK, Zheng ZJ, Zonies D, Lopez AD, Murray CJ, AlMazroa M, Memish ZA (2012) Years lived with disability (YLDs) for 1160 sequelae of 289 diseases and injuries 19902010: a systematic analysis for the Global Burden of Disease Study 2010. Lancet 380(9859):2163-2196. https://doi.org/10. 1016/S0140-6736(12)61729-2

2. Sowers M (2001) Epidemiology of risk factors for osteoarthritis: systemic factors. Curr Opin Rheumatol 13(5):447-451

3. Palazzo C, Nguyen C, Lefevre-Colau MM, Rannou F, Poiraudeau S (2016) Risk factors and burden of osteoarthritis. Ann Phys Rehabil Med 59(3):134-138. https://doi.org/10.1016/j.rehab.2016.01.006

4. Pereira D, Peleteiro B, Araujo J, Branco J et al (2011) The effect of osteoarthritis definition on prevalence and incidence estimates: a systematic review. Osteoarthr Cartil 19(11):1270-1285. https:// doi.org/10.1016/j.joca.2011.08.009

5. Franklin J, Ingvarsson T, Englund M, Lohmander S (2010) Association between occupation and knee and hip replacement due to osteoarthritis: a case-control study. Arthritis Res Ther 12(3):R102-R109. https://doi.org/10.1186/ar3033

6. Department of Clinical Sciences Orthopedics LU (2018) Swedish knee arthroplasty register. Annual Report 2018. www.myknee.se. Accessed December 11th 2018

7. Nemes S, Rolfson O, W-Dahl A, Garellick G et al (2015) Historical view and future demand for knee arthroplasty in Sweden. Acta Orthop 86(4):426-431. https://doi.org/10.3109/17453674.2015. 1034608

8. Lofvendahl S, Bizjajeva S, Ranstam J, Lidgren L (2011) Indications for hip and knee replacement in Sweden. J Eval Clin Pract 17(2): 251-260. https://doi.org/10.1111/j.1365-2753.2010.01430.x

9. Bachmeier CJ, March LM, Cross MJ, Lapsley HM, Tribe KL, Courtenay BG, Brooks PM, Arthritis Cost and Outcome Project Group (2001) A comparison of outcomes in osteoarthritis patients undergoing total hip and knee replacement surgery. Osteoarthr Cartil 9(2):137-146

10. Gundry M, Hopkins S, Knapp K (2017) A Review on bone mineral density loss in total knee replacements leading to increased fracture risk. Clin Rev Bone Miner Metab 15(4):162-174. https://doi.org/ 10.1007/s12018-017-9238-4

11. Geusens PP, van den Bergh JP (2016) Osteoporosis and osteoarthritis: shared mechanisms and epidemiology. Curr Opin Rheumatol 28(2):97-103. https://doi.org/10.1097/BOR.0000000000000256

12. Okano K, Aoyagi K, Enomoto H, Osaki M, Chiba K, Yamaguchi K (2014) Bone mineral density in patients with destructive arthrosis of the hip joint. J Bone Miner Metab 32(3):312-316. https://doi.org/ 10.1007/s00774-013-0501-6
13. Prieto-Alhambra D, Nogues X, Javaid MK, Wyman A, Arden NK, Azagra R, Cooper C, Adachi JD, Boonen S, Chapurlat RD, Compston JE, Gehlbach SH, Greenspan SL, Hooven FH, Netelenbos JC, Pfeilschifter J, Rossini M, Sambrook PN, Silverman S, Siris ES, Watts NB, Díez-Pérez A (2013) An increased rate of falling leads to a rise in fracture risk in postmenopausal women with self-reported osteoarthritis: a prospective multinational cohort study (GLOW). Ann Rheum Dis 72(6):911-917. https://doi.org/10.1136/annrheumdis-2012-201451

14. Hernlund E, Svedbom A, Ivergard M, Compston J et al (2013) Osteoporosis in the European Union: medical management, epidemiology and economic burden. A report prepared in collaboration with the International Osteoporosis Foundation (IOF) and the European Federation of Pharmaceutical Industry Associations (EFPIA). Arch Osteoporos 8(1-2):136. https://doi.org/10.1007/ s11657-013-0136-1

15. Gunnes M, Lehmann EH, Mellstrom D, Johnell O (1996) The relationship between anthropometric measurements and fractures in women. Bone 19(4):407-413

16. Lalmohamed A, Opdam F, Arden NK, Prieto-Alhambra D, van Staa T, Leufkens HG, de Vries F (2012) Knee arthroplasty and risk of hip fracture: a population-based, case-control study. Calcif Tissue Int 90(2):144-150. https://doi.org/10.1007/s00223-0119558-1

17. Prieto-Alhambra D, Javaid MK, Maskell J, Judge A, Nevitt M, Cooper C, Arden NK (2011) Changes in hip fracture rate before and after total knee replacement due to osteoarthritis: a populationbased cohort study. Ann Rheum Dis 70(1):134-138. https://doi.org/ 10.1136/ard.2010.131110

18. Mautalen CA, Vega EM, Einhorn TA (1996) Are the etiologies of cervical and trochanteric hip fractures different? Bone 18(3 Suppl): $133 \mathrm{~S}-137 \mathrm{~S}$

19. Ludvigsson JF, Andersson E, Ekbom A, Feychting M, Kim JL, Reuterwall C, Heurgren M, Olausson PO (2011) External review and validation of the Swedish national inpatient register. BMC Public Health 11:450. https://doi.org/10.1186/1471-2458-11-450

20. Vala $\mathrm{CH}$, Oden A, Lorentzon M, Sundh V et al (2017) Increased risk of hip fracture among spouses-evidence of a homogamy effect. Osteoporos Int 28(1):95-102. https://doi.org/10.1007/s00198-0163738-9

21. Johansson H, Hongslo Vala C, Oden A, Lorentzon M et al (2018) Low risk for hip fracture and high risk for hip arthroplasty due to osteoarthritis among Swedish farmers. Osteoporos Int 29(3):741749. https://doi.org/10.1007/s00198-017-4355-y

22. Breslow NE, Day NE (1987) Statistical methods in cancer research. Volume II-The design and analysis of cohort studies. IARC Sci Publ 82:1-406

23. Yamamoto Y, Turkiewicz A, Wingstrand H, Englund M (2015) Fragility fractures in patients with rheumatoid arthritis and osteoarthritis compared with the general population. J Rheumatol 42(11): 2055-2058. https://doi.org/10.3899/jrheum.150325

24. Arnold JB, Walters JL, Ferrar KE (2016) Does physical activity increase after total hip or knee arthroplasty for osteoarthritis? A systematic review. J Orthop Sports Phys Ther 46(6):431-442. https://doi.org/10.2519/jospt.2016.6449

25. Lo CWT, Tsang WWN, Yan CH, Lord SR et al (2019) Risk factors for falls in patients with total hip arthroplasty and total knee arthroplasty: a systematic review and meta-analysis. Osteoarthr Cartil 27(7):979-993. https://doi.org/10.1016/j.joca.2019.04.006

26. Chan ACM, Jehu DA, Pang MYC (2018) Falls after total knee arthroplasty: frequency, circumstances, and associated factors-a prospective cohort study. Phys Ther 98(9):767-778. https://doi. org $/ 10.1093 / \mathrm{ptj} / \mathrm{pzy} 071$

27. Caffarelli C, Alessi C, Nuti R, Gonnelli S (2014) Divergent effects of obesity on fragility fractures. Clin Interv Aging 9:1629-1636. https://doi.org/10.2147/CIA.S64625 
28. Walsh JS, Vilaca T (2017) Obesity, Type 2 Diabetes and bone in adults. Calcif Tissue Int 100(5):528-535. https://doi.org/10.1007/ s00223-016-0229-0

29. Godziuk K, Prado CM, Woodhouse LJ, Forhan M (2018) The impact of sarcopenic obesity on knee and hip osteoarthritis: a scoping review. BMC Musculoskelet Disord 19(1):271. https://doi.org/10. 1186/s12891-018-2175-7

30. den Uyl D, Nurmohamed MT, van Tuyl LH, Raterman HG et al (2011) (Sub)clinical cardiovascular disease is associated with increased bone loss and fracture risk; a systematic review of the association between cardiovascular disease and osteoporosis. Arthritis Res Ther 13(1):R5. https://doi.org/10.1186/ar3224

31. Sadeghi O, Saneei P, Nasiri M, Larijani B et al (2017) Abdominal obesity and risk of hip fracture: a systematic review and metaanalysis of prospective studies. Adv Nutr 8(5):728-738. https:// doi.org/10.3945/an.117.015545

32. Harvey NC, Oden A, Orwoll E, Lapidus J et al (2018) Measures of physical performance and muscle strength as predictors of fracture risk independent of FRAX, falls, and aBMD: a meta-analysis of the osteoporotic fractures in men (MrOS) study. J Bone Miner Res 33(12):2150-2157. https://doi.org/10.1002/jbmr.3556

33. Meyer HE, Willett WC, Flint AJ, Feskanich D (2016) Abdominal obesity and hip fracture: results from the Nurses' Health Study and the Health Professionals Follow-up Study. Osteoporos Int 27(6): 2127-2136. https://doi.org/10.1007/s00198-016-3508-8

34. Szots K, Pedersen PU, Hordam B, Thomsen T et al (2015) Physical health problems experienced in the early postoperative recovery period following total knee replacement. Int J Orthop Trauma Nurs 19(1):36-44. https://doi.org/10.1016/j.ijotn.2014.03.005
35. Uvehammer J (2001) Knee joint kinematics, fixation and function related to joint area design in total knee arthroplasty. Acta Orthop Scand Suppl 72(299):1-52

36. Donell $\mathrm{S}$ (2018) Patellar tracking in primary total knee arthroplasty. EFORT Open Rev 3(4):106-113. https://doi.org/10.1302/20585241.3.170036

37. Weidow J, Tranberg R, Saari T, Karrholm J (2006) Hip and knee joint rotations differ between patients with medial and lateral knee osteoarthritis: gait analysis of 30 patients and 15 controls. J Orthop Res 24(9):1890-1899. https://doi.org/10.1002/jor.20194

38. Weidow J, Karrholm J, Saari T, McPherson A (2007) Abnormal motion of the medial femoral condyle in lateral knee osteoarthritis. Clin Orthop Relat Res 454:27-34. https://doi.org/10.1097/BLO. 0b013e31802bab25

39. Michaelsson K, Weiderpass E, Farahmand BY, Baron JA et al (1999) Differences in risk factor patterns between cervical and trochanteric hip fractures. Swedish Hip Fracture Study Group. Osteoporos Int 10(6):487-494

40. Weidow J, Mars I, Karrholm J (2005) Medial and lateral osteoarthritis of the knee is related to variations of hip and pelvic anatomy. Osteoarthr Cartil 13(6):471-477. https://doi.org/10.1016/j.joca. 2005.01.009

41. Chatziagorou G, Lindahl H, Garellick G, Karrholm J (2018) Incidence and demographics of 1751 surgically treated periprosthetic femoral fractures around a primary hip prosthesis. Hip Int. https://doi.org/10.1177/1120700018779558

Publisher's note Springer Nature remains neutral with regard to jurisdictional claims in published maps and institutional affiliations. 